First publ. in: Flavins and flavoproteins 1990 : proceedings of the tenth International Symposium,

Como, Italy, July 15 - 20, 1990, pp. 311-314

\title{
AROMATIC SUBSTRATE ANALOGUES AS MECHANISTIC PROBES FOR MEDIUM-CHAIN ACYL-COA DEHYDROGENASES
}

\author{
Stefan Engst and Sandro Ghisla
}

Faculty of Biology, University of Konstanz, PO Box 5560, D-7750 Konstanz, FRG

\section{Introduction}

Some aliphatic substrate analogues have been useful in the study of the active site of medium-chain acyl-COA dehydrogenase (MCADH), e.g. 3-ketoacyl-COA and 3-thiaoctanoyl-COA [1,2], which cannot be dehydrogenated, but deprotonate at $\boldsymbol{\alpha}$-position. They show characteristic longwavelength bands upon binding to $\mathrm{MCADH}$, which have been attributed to formation of charge transfer complexes between the $\alpha$-deprotonated (anionic) forms of the analogues and the oxidized enzyme flavin.

We have sought methods to study the ways in which the enzyme lowers the $\mathrm{pK}_{\mathrm{a}}$ for the (transient) formation of a substrate carbanion in the step initiating catalysis. Promising approaches are the use of "pH indicators", i.e. of compounds sensitive to the presence of charges and dipoles, which are also substrate analogues, 4-Nitrophenylacetyl-CoA and 4 aminobenzoyl-COA are such compounds. Their mode of interaction with MCADH yields information about active center functional groups and the flavin environment.

Results and Discussion

4-Nitrophenylacetyl COA binds to recombinant human MCADH $\left(\mathrm{K}_{\mathrm{d}}=2.3 \cdot 10^{-5} \mathrm{M}\right.$ ) and induces formation of an intense longwavelength band $\left(\lambda_{\max } \sim 740 \mathrm{~nm}, \varepsilon_{740}=4100 \mathrm{M}^{-1} \mathrm{~cm}{ }^{1}\right.$, Fig. 1$)$. This 
is compatible with formation of the $\boldsymbol{\alpha}$-deprotonated (anionic) form of 4-nitrophenylacetyl-CoA at the active site of the enzyme. In addition to this, a strong increase in absorbance at $\sim 500 \mathrm{~nm}$ occurs (see difference spectrum, inset Fig. $1 ; \lambda_{\max }$ $\sim 497 \mathrm{~nm}, \varepsilon \sim 12400 \mathrm{M}^{-1} \mathrm{~cm}^{1}$ ), which can hardly be attributed to a simple perturbation of the oxidized flavin spectrum. It is therefore ascribed to the absorption of the anionic, 4-nitrophenylacetyl chromophore itself (cf. fig. 3b). Supportive evidence is the formation of an intense red color immediately after treatment of 4-nitrophenylacetyl-CoA with $1 \mathrm{M} \mathrm{NaOH}$. This color is assumed to correspond to deprotonation of the analogue and allows a rough estimation of the $\mathrm{pKa}_{\mathrm{a}}$ as 13-15. The color rapidly disappears, most likely because of hydrolysis of the thioester function.

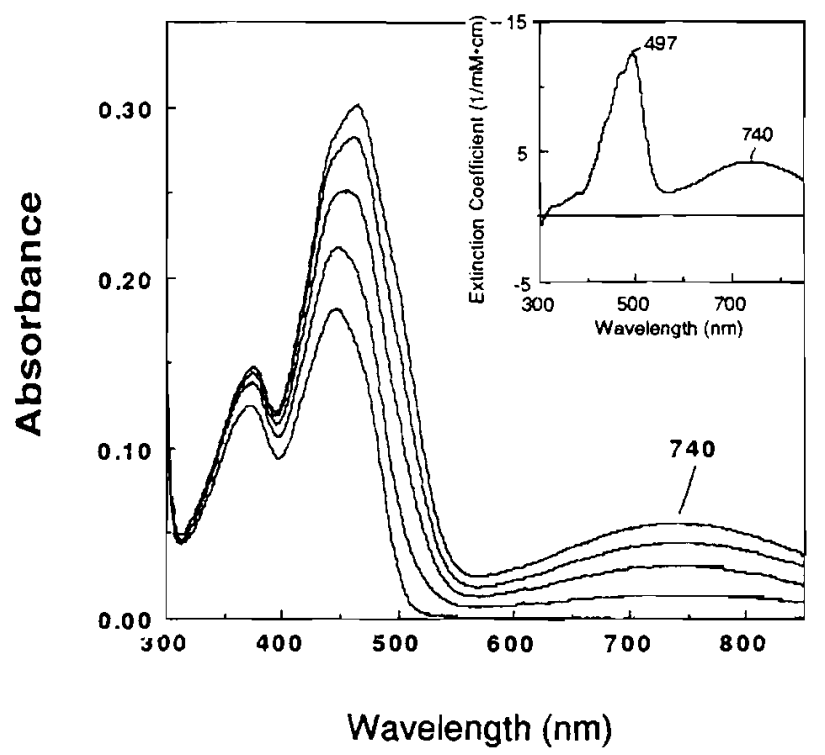

Fig.1: Addition of $0,0.73,2.32,10.3$ and 39.4 equivalents of 4-nitrophenylacetyl-COA to recombinant human MCADH $\left[1.37 \cdot 10^{-5} \mathrm{M}\right]$ in $100 \mathrm{mM}$ potassium phosphate $\mathrm{pH}$. The analogue was added to sample and reference, all spectra are corrected for dilution. The inset shows the difference spectrum between human MCADH, fully complexed with 4-nitrophenylacetylCOA and uncomplexed enzyme. 
The $\pi-\pi$ transition of 4 -aminobenzoyl-COA is at $-318 \mathrm{~nm}$ $\left(\varepsilon_{318}=16400 \mathrm{M}^{-1} \mathrm{~cm}^{-1}\right.$, Fig. 2, inset). Upon binding to MCADH this band disappears, while a new, more intense band appears at $365 \mathrm{~nm}$ (Fig. 2, $\mathrm{K}_{\mathrm{d}}=5.2 \cdot 10^{-5} \mathrm{M}$ ). This $47 \mathrm{~nm}$ red-shift most probably reflects a strong polarization of the thioestercarbonyl moiety which considerably increases its electron withdrawing properties. An enzyme interaction possibly causing this (a hydrogen bridge, dipole or a positive charge) is depicted in fig. $3 \mathrm{a}$. In line with this, it is well known that substituted anilines show a red shift of the $\pi-\pi$ transition on introduction of substituents with increasing electron withdrawing properties at position 4. A similar effect is exhibited by 4-thia-trans-2-octenoyl-COA [2].

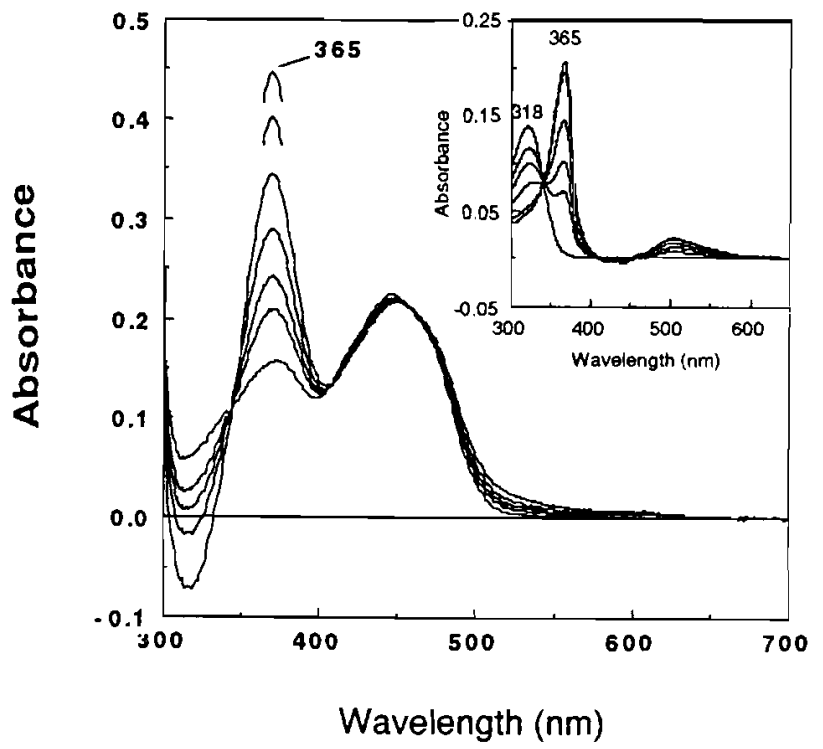

Fig. 2: Addition of $0,0.76,1.37,2.75,5.47,12.34$ and 39.8 equivalents of 4 -aminobenzoyl-CoA to human $\mathrm{MCADH}$ [1.65.10.5 $\mathrm{M}$ ] in $100 \mathrm{mM}$ potassium phosphate $\mathrm{pH}$ 8, inset: addition of $0,0.8$, $1.33,2.26,4.92$ and 6.52 equivalents of pig kidney $\mathrm{MCADH}$ to 4-aminobenzoyl-COA $\left[8.4 \cdot 10^{-6} \mathrm{M}\right]$. Additions were made to sample and reference, all spectra are corrected for dilution. 
a)

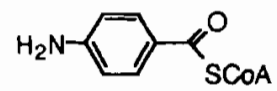

$$
\lambda_{\text {max }}=318 \mathrm{~nm}
$$

MCADH

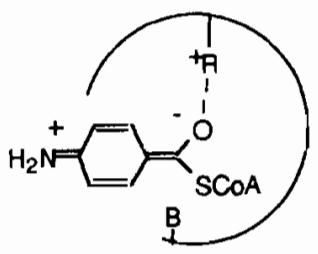

$\lambda_{\max }=365 \mathrm{~nm}$

\section{MCADH}

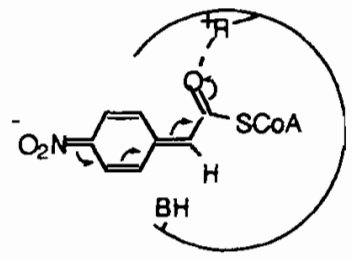

$\lambda_{\max }=497 \mathrm{~nm}$

$$
\lambda_{\text {max }} \approx 290 \mathrm{~nm}
$$

(shoulder)

Proposed interaction of active site residues with 4 -aminobenzoyl-COA and 4-nitrophenylacetyl-COA upon binding to MCA.DH .

\section{Conclusions}

These results support the concept of abstraction of $\alpha \cdot \mathrm{C} \cdot \mathrm{H}$ as a proton, and of acidification of this function by interaction with the protein at the active site. The $\mathrm{pk}$ shift induced in the case of 4-nitrophenylacetyl-CoA is at least $6 \mathrm{pk}$ units. The behavior of 4 -aminobenzoyl-CoA is in line with the presence of an electron withdrawing group interacting between the thioester-carbonyl function and the protein.

\section{References}

1. Powell, P. J., S. Lau, D. Killian and C. Thorpe, 1987, Biochemistry. 26, 3704-3710.

2. Lau, S., R. K. Brantley and C. Thorpe, 1988, Arch. Biochem. Biophys. 27. 5089-5095. 